\title{
The reasons for extraction of permanent teeth in Scotland: a 15-year follow-up
} study

\author{
L. K. McCaul, ' W. M. M. Jenkins, ${ }^{2}$ and E. J. Kay, ${ }^{3}$
}

\begin{abstract}
Aims Although Scotland has the highest proportion of edentulous adults in the UK, the frequency of edentulousness has fallen by $21 \%$ during the last 20 years. This study, carried out in 1999 , was designed to establish whether the reasons for tooth loss have also changed since 1984 when they were last determined. Methods The Scottish Dental Practice Board provided the names of every fourth dentist on its list among which 425 general dental practitioners were identified. They were asked to record permanent tooth extractions for 1 week, specifying the age, sex and dental attendance of patients who underwent extractions and the reasons for these extractions. 352 dentists took part: a response rate of $82.8 \%$.
\end{abstract}

Results The study confirmed that there has been a reduction in the number of extractions between 1984 and 1999: there were $25 \%$ fewer teeth extracted per patient and $30 \%$ fewer per dentist per week. From 0-20 years of age, orthodontics has replaced caries as the commonest reason for extraction and in all age groups over 20 years, caries has become the commonest reason in contrast to 1984 when periodontal disease was the principal reason in patients over 40 years old.

Conclusions Caries and its sequelae remain the most important cause of tooth loss throughout adult life in Scotland and, therefore, caries prevention and maintenance of restorations are of great importance at all ages.

$\mathrm{N}$ ationwide surveys to determine the reasons for extraction have been carried out in several countries (Table 1). The reasons for tooth loss in Scotland were unknown until 1986 when Kay and Blinkhorn published the findings of a study which they had carried out in $1984 .{ }^{1}$ In that study a sample of general dental practitioners was asked to record permanent tooth extractions for 1 week specifying the age, gender and dental attendance pattern for each patient and the reasons for each extraction. The results showed that while caries was the leading cause for tooth loss overall, periodontal disease assumed greater importance in patients over 40 years old. Age, gender and dental attendance patterns also influenced the distribution of extractions.

The Adult Dental Health Survey carried out in the United Kingdom in 1998 showed that the proportion of edentulous adults in Scotland fell from $39 \%$ in 1978 to $26 \%$ in 1988 and to $18 \%$ in $1998 .^{2}$ Within the 45-54 year age group, the proportion who were edentu-

${ }^{1}$ Senior Registrar in Restorative Dentistry, ${ }^{2}$ Consultant in Restorative Dentistry, Glasgow Dental Hospital and School, 378 Sauchiehall Street, Glasgow G2 3JZ

${ }^{3}$ Professor of Dental Health Services Research, Turner Dental School, University Dental Hospital of Manchester, Higher Cambridge Street, Manchester M15 6FH ${ }^{*}$ Correspondence to: L. K. McCaul

email:lorna.mccaul@ntlworld.com

REFEREED PAPER

Received 22.05.00; Accepted 15.01.01

(C) British Dental Journal 2001; 190: 658-662 lous at these time points fell from $54 \%$ to $33 \%$ to $13 \%$. It seems likely, therefore, that the reasons for tooth loss in Scotland might have changed in the 15 years since they were first determined.

In order to facilitate planning for dental health services and to develop strategies to continue the reduction in tooth loss it is important to identify the factors which have resulted in such loss.

The aim of this study was to determine the current reasons for tooth extractions in Scotland and their relative importance.

\section{Method}

The Scottish Dental Practice Board was asked to provide the names and addresses of every fourth dentist on its list, stratified by health board area. The aim was to obtain a sample of $25 \%$ of Scottish general dental practitioners. Emergency only clinics were excluded. These dentists were forwarded a covering letter explaining the nature of the study, a record form and a reply paid envelope. They were asked to record permanent tooth extractions for one working week on one single form. For each patient having one or more teeth extracted, the number, type and reason for each extraction were recorded. Records were obtained only for those patients having an extraction.

After an interval of 1 month a second wave of forms (with a suitably modified covering letter) was sent out to the non-respondents. After a further month all the remaining non-respondents were telephoned by one of the authors and encouraged to participate.

To facilitate comparison with the 1984 study the same extraction criteria were used and are shown in Table 2. The dentists were asked to give only one reason for each tooth removed and to record each patient's age, gender and dental attendance pattern. Regular attendance was defined as attendance at the surgery in the past 2 years for routine examination. Patients attending solely for pain relief and patients attending for the first time were deemed irregular attenders.

\section{Results}

A total of 479 forms were issued. It became clear from some of the forms returned that a number of the dentists receiving the form were not eligible to complete it ( 13 were orthodontists or community dentists). Further, 41 forms could not be completed because the intended recipients had either left the practice or were on maternity leave or were deceased. Thus 425 forms were received by general dental practitioners. A total of 352 forms were completed and returned. This represents $73.5 \%$ of the 479 forms originally issued or an $82.8 \%$ response rate from the 425 eligible dentists who received a form. This gave a final sample of about $20 \%$ of Scotland's general dental practitioners. There are 13 health board areas in Scotland and there were no significant differences in the response rate for each health board area.

All targeted dentists were contacted either by letter or telephone in the course of the study and an attempt was made to clarify the reasons for non-participation of eligible dentists. These included lack of time or lack of interest, working part time only and being on holiday.

Of the 352 returned forms, 2 were completed incorrectly and, 
Table I Results of national cross-sectional studies of reasons for extraction

\begin{tabular}{lcccl}
\hline Country & $\begin{array}{c}\text { Year of } \\
\text { publication }\end{array}$ & $\begin{array}{c}\text { \% extracted for } \\
\text { caries }\end{array}$ & $\begin{array}{c}\text { \% extracted for } \\
\text { periodontitis }\end{array}$ & Author \\
\hline Finland & 1984 & 60 & 18 & Ainamo \\
France & 1985 & 49 & 32 & Cahen \\
Scotland & 1986 & 50 & 21 & Kay \\
England/Wales & 1988 & 48 & 27 & Agerholm \\
Norway & 1988 & 35 & 19 & Klock \\
Canada & 1991 & 63 & 34 & Stephens \\
Germany & 1993 & 20.7 & 27.3 & Reich \\
Singapore & 1996 & 35.4 & 35.8 & Ong \\
Italy & 1996 & 33.4 & 33.1 & Angelillo \\
Canada & 1997 & 28.9 & 35.9 & Murray \\
\hline
\end{tabular}

Table 2 Extraction criteria

\begin{tabular}{|c|c|}
\hline Extraction reason & Criteria \\
\hline Caries & $\begin{array}{l}\text { Initial and recurrent caries, all sequelae of caries including } \\
\text { extraction of roots where the crown was lost through } \\
\text { caries and teeth fracturing due to weakening by caries. } \\
\text { Failed root treatment where the tooth was initially root } \\
\text { treated because of caries. }\end{array}$ \\
\hline $\begin{array}{l}\text { Periodontal } \\
\text { disease }\end{array}$ & $\begin{array}{l}\text { Where pain, loss of function or pocketing due to } \\
\text { periodontal disease requires that the tooth be extracted. }\end{array}$ \\
\hline Orthodontic & $\begin{array}{l}\text { Teeth extracted to prevent or correct malocclusion, be } \\
\text { they impacted, incompletely erupted or supernumerary. }\end{array}$ \\
\hline Trauma & $\begin{array}{l}\text { Teeth lost as a result of trauma including jaw fractures } \\
\text { (fractured restorations should be placed in the caries } \\
\text { category). }\end{array}$ \\
\hline Pre-prosthetic & $\begin{array}{l}\text { Teeth which are extracted because their removal } \\
\text { facilitates a better prosthetic restoration. }\end{array}$ \\
\hline Patient request & $\begin{array}{l}\text { Teeth extracted because the patient prefers extraction to } \\
\text { other treatments or requests a clearance and dentures. } \\
\text { Also in this category, extractions performed due to the } \\
\text { patient's behaviour or fear which prevents conservative } \\
\text { care being carried out. }\end{array}$ \\
\hline Pericoronitis & $\begin{array}{l}\text { Persistent inflammation around third molars which } \\
\text { necessitates removal of one or more third molar. }\end{array}$ \\
\hline Other reason & $\begin{array}{l}\text { If the reasons for extracting a tooth are not encompassed } \\
\text { by the above categories the reason should be stated } \\
\text { clearly. }\end{array}$ \\
\hline
\end{tabular}

therefore, discarded and data from the remaining forms were analysed.

The age and sex distribution of patients and extracted teeth is shown in table 3. Overall, 350 dentists had extracted 2,558 teeth (mean 7.3 extractions per dentist per week) from 1,730 patients (mean 1.5 extractions per patient) of whom 818 (47.3\%) were female and 912 (52.3\%) were male. Nineteen respondents had not carried out any permanent tooth extractions during the week of the study. Males having teeth extracted were most commonly in the 21-30 year age group and females in the 31-40 year age group. Of the teeth removed, 1,352 were removed from males (mean 1.48 extractions per male patient). Female patients had 1,206 teeth extracted (mean 1.47 extractions per female patient).

The main reason for extraction was caries and its sequelae (54.7\%). Periodontal disease accounted for $16.7 \%$ of extractions. Orthodontics accounted for $9.9 \%$ of extractions and $8.4 \%$ were preprosthetic. Patient request was the reason for $5.1 \%$ of extractions and $2.5 \%$ were for another, unspecified reason. Pericoronitis and trauma accounted for $1.8 \%$ and $1.0 \%$ of extractions respectively. The extractions for caries occurred in $59.4 \%$ of the population sample; those for periodontal disease occurred in $15.6 \%$.

Figure 1 shows the percentage distribution of extraction reasons for males and females separately. Caries was the main reason for extraction in both males and females. It accounted for $60.6 \%$ of extractions in males and $48.1 \%$ of extractions in females. By contrast, extractions for periodontal and orthodontic reasons accounted for a greater proportion of extractions in females $(18.7 \%$ and $12.7 \%$ respectively) than in males (14.9\% and $7.3 \%)$.

Figure 2 shows that the reasons for tooth loss varied within different age groups: caries accounted for the majority of extractions in each age group over 20 years old and reached $84.9 \%$ of extractions in the 21-30 year age group. The age group with the highest proportion of extractions for periodontal reasons was $51-60$ years (35.2\%) but this was still less than for caries $(39.5 \%$ of the extractions in this age group). The main reason for extraction in patients under 20 years old was orthodontics ( $51.7 \%$ of extractions in $0-10$ year olds and $55.7 \%$ of extractions in 11-20 year olds) with caries being the second most common reason $(44.8 \%$ of extractions in $0-10$ year olds and $37.6 \%$ in $11-20$ year olds). The age group 71 years and over had the highest percentage of extractions for pre-prosthetic reasons

Table 3 Age and sex distribution of patients and extracted teeth

\begin{tabular}{|c|c|c|c|c|c|c|}
\hline \multirow{2}{*}{$\begin{array}{l}\text { Age } \\
\text { group } \\
\text { (years) }\end{array}$} & \multicolumn{2}{|c|}{ Males } & \multicolumn{2}{|c|}{ Females } & \multicolumn{2}{|c|}{ Both Sexes } \\
\hline & Patients & Teeth & Patients & Teeth & Patients & Teeth \\
\hline $0-10$ & 8 & II & 14 & 18 & 22 & 29 \\
\hline $11-20$ & 137 & 205 & 136 & 204 & 273 & 409 \\
\hline $21-30$ & 190 & 231 & 137 & 186 & 327 & 417 \\
\hline $31-40$ & 164 & 219 & 159 & 208 & 323 & 427 \\
\hline $4 I-50$ & 154 & 214 & $15 \mid$ & 234 & 305 & 448 \\
\hline $5 I-60$ & 122 & 214 & 98 & 161 & 220 & 375 \\
\hline $6 I-70$ & 97 & 192 & 66 & III & 163 & 303 \\
\hline $71+$ & 40 & 66 & 57 & 84 & 97 & 150 \\
\hline Total & 912 & $\mathrm{I}, 352$ & 818 & 1,206 & $\mathrm{I}, 730$ & 2,558 \\
\hline
\end{tabular}




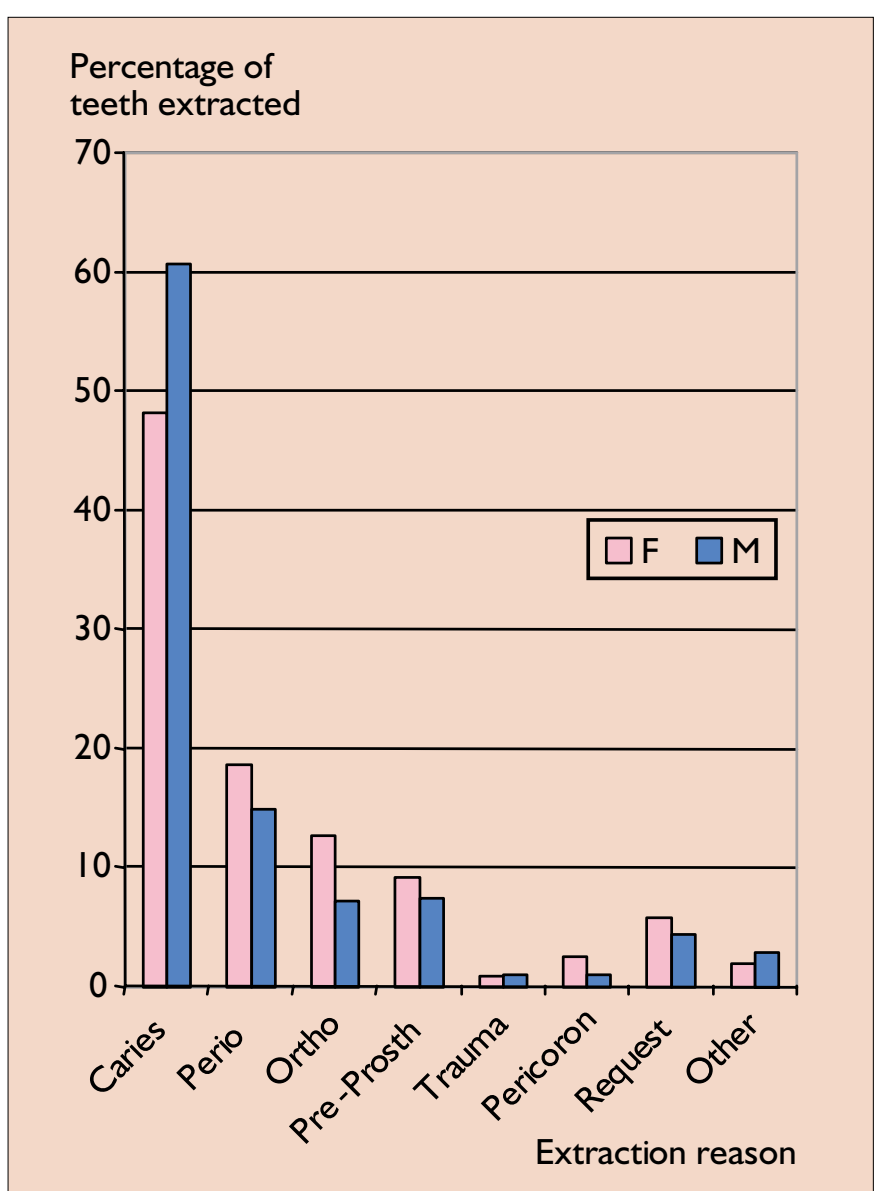

Fig. I Percentage distribution of extraction reasons for males and females

(23.3\%). The remaining reasons for extractions, namely 'patient request', 'pericoronitis', 'trauma' and 'other unspecified reasons' made up a smaller proportion of extractions and, for clarity, are combined under the heading 'other ' in Figure 3. Extractions at the patient's request were most common in the $31-40$ and $61-70$ year age groups, accounting for $9.6 \%$ of extractions in each of the two age groups. Extractions for pericoronitis were mostly from 21-30 year old patients but accounted for only $4.8 \%$ of extractions in this age group. Comparison of data from the 1984 study is presented later.
Table 4 Distribution of extraction reasons for regular and irregular attenders

\begin{tabular}{l|rr|rr}
\hline \multirow{2}{*}{$\begin{array}{l}\text { Extraction } \\
\text { Reason }\end{array}$} & $n$ & \multicolumn{2}{c}{ Regular } & \multicolumn{2}{c}{ Irregular } \\
& & & & $\%$ \\
\hline & 588 & 42 & 811 & 70 \\
Peries & 260 & 19 & 167 & 15 \\
Orthodontics & 240 & 17 & 12 & 1 \\
Pre-prosthetic & 139 & 10 & 76 & 7 \\
Trauma & 16 & 1 & 10 & $<1$ \\
Patient request & 73 & 5 & 58 & 5 \\
Pericoronitis & 36 & 3 & 9 & $<1$ \\
Other & 52 & 4 & 11 & $<1$ \\
\hline Total & 1,404 & 100 & 1,154 & 100 \\
\hline
\end{tabular}

It was found that $51.5 \%$ of males and $65.6 \%$ of females were regular attenders. The effect of dental attendance pattern on the number and distribution of extractions was examined (see Table 4). Caries accounted for $42 \%$ of teeth removed from regular attenders and $70 \%$ of the teeth removed from irregular attenders. Periodontal disease was the reason for $19 \%$ of extractions from regular attenders and $15 \%$ of extractions from irregular attenders. Orthodontics was the reason for $17 \%$ of extractions from regular attenders and $1 \%$ of extractions from irregular attenders.

Table 5 summarises the main differences between the 1984 and 1999 studies. In 1999 there were approximately 25\% fewer teeth extracted per patient and 30\% fewer per dentist per week. The relative percentage of extractions caused by caries and for orthodontic reasons has increased in both regular and irregular attenders and that caused by periodontal disease and for pre-prosthetic reasons has reduced in both groups.

The 1984 and 1999 studies are further compared in Figure 3 which demonstrates that, in the age groups 0-20 years, orthodontics has replaced caries as the commonest reason for extraction; and in all age groups over 20 years, caries has become the commonest reason for extraction, in contrast to the previous study where periodontal disease became the principal reason in patients over 40 years old.

\section{Discussion}

To ensure the validity of any questionnaire survey there must be an adequate response rate. ${ }^{3}$ Certain features of study design have been found to improve response rate and steps were taken to include as many of these as possible. ${ }^{4}$ These included simple, short question-
Fig. 2 Percentage distribution of extractions in each age group in 1999. * Other: this group comprises trauma, pericoronitis, patient request and other unspecified reasons and also for clarity of presentation, periodontal disease, orthodontics and preprosthetic extractions where, individually, these amounted to less than $I \%$ of the total.
Percentage of the teeth extracted (\%)

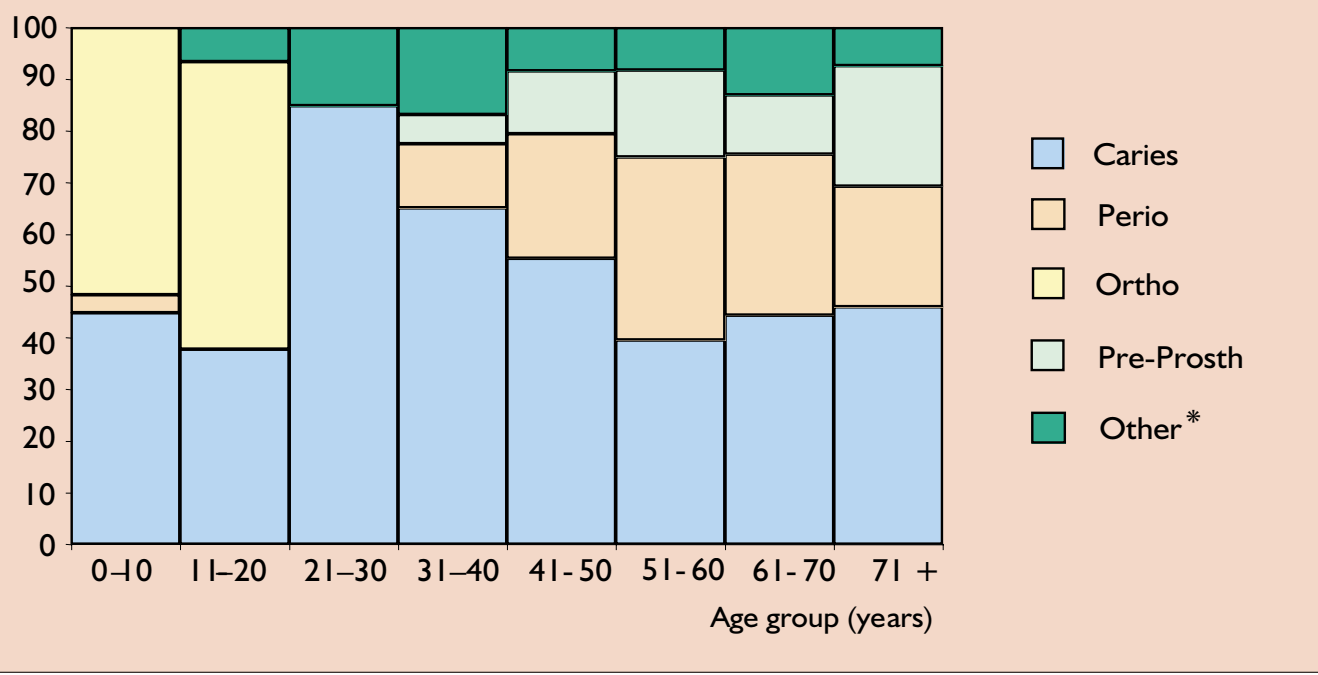


Fig. 3 Comparison of the percentage distribution of extractions in each age group in 1984 and 1999. *Other: this group comprises trauma, pericoronitis, patient request and other unspecified reasons and also for clarity of presentation, periodontal disease, orthodontics and preprosthetic extractions where, individually, these amounted to less than $1 \%$ of the total

Percentage of teeth extracted (\%)

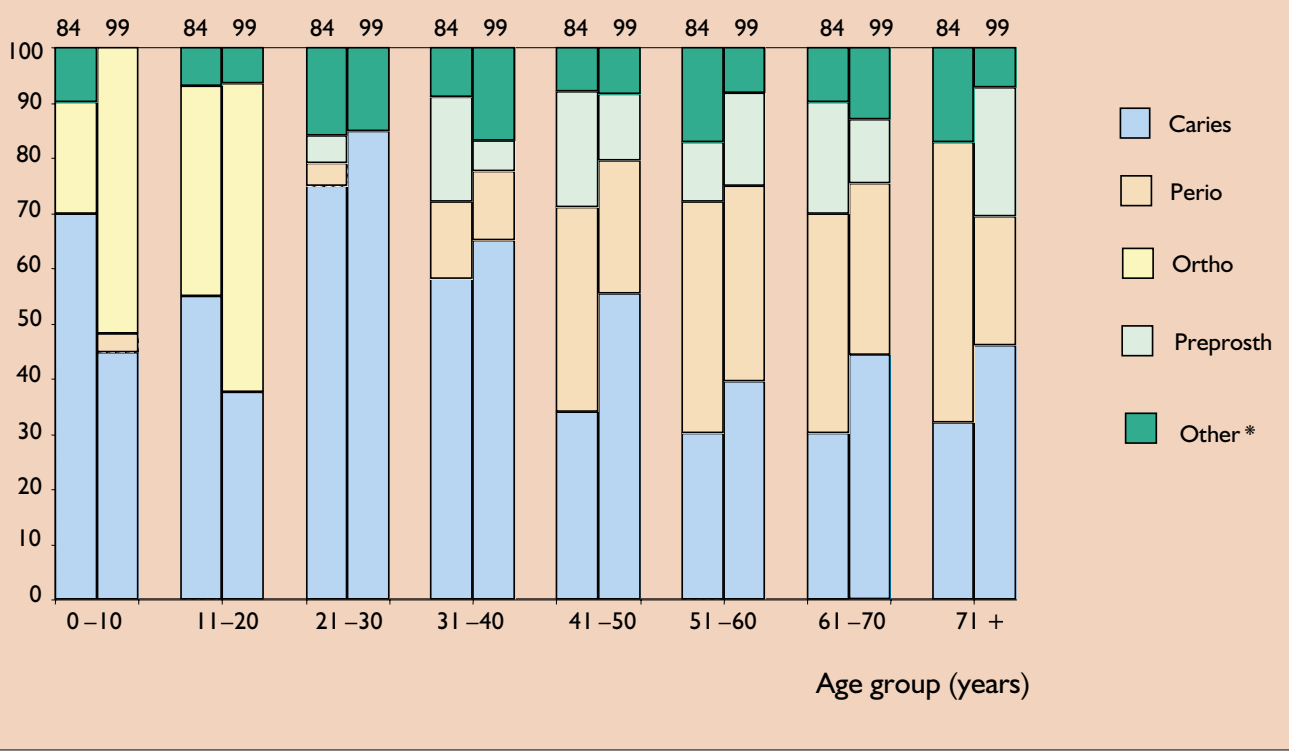

naire design, care with covering letter composition (ie request for support, usefulness of study, importance of respondent to study success), personalisation of correspondence, assurance of confidentiality, addition of titles of senders' names, inclusion of reply-paid return envelopes and use of repeated follow up. Adherence to these guidelines may have contributed to the relatively high response rate. As the response rates in each health board area were similar the sample population may be taken as representative of Scotland as a whole. Care must be taken, however, when interpreting the results as there are inevitably sources of bias. Each dentist collected data for a 1-week period but the study was spread over 3 months and for this reason it must be assumed that there is no seasonal variation in extraction trends as shown by Morita et al. ${ }^{5} \mathrm{~A}$ further assumption was that each dentist's choice of extraction reason would be valid, an expectation which was supported by a recent study. ${ }^{6}$

Each participating dentist carried out extractions on varying numbers of patients, some of whom required multiple extractions. Therefore, the results must be interpreted with caution, particularly when comparing the 1984 and 1999 studies.

The data presented in Table 1 reveal that among all studies published since 1984, reported rates of extractions caused by caries ranged from $21 \%$ to $60 \%$ and the relative importance of caries and periodontal disease in each study varied considerably. ${ }^{1,7-15}$ These variations, however, are at least partly attributable to methodological differences. This is illustrated by comparison of the two Canadian studies. Thus, Stephens et al., ${ }^{15}$ who reported their findings in 1991, collected their data from patients attending a Canadian dental teaching hospital; the other Canadian study, carried out a few years later by a different team of investigators, comprised a questionnaire survey of general dental practitioners with a response rate of only $27.7 \% .^{11}$ In addition, while Ong et al. showed that caries and periodontal disease were of equal importance, the majority of their sample was aged less than 40 years. ${ }^{13}$ Thus, comparison of tooth extraction data between different countries is fraught with difficulty.

In the present study, data on tooth extractions from children and adults of all ages were recorded by GDPs (by $82.8 \%$ of those dentists who were contacted and invited to participate). By using a similar methodology, valid comparisons to the earlier Scottish study could be made.

In 1999, caries with its sequelae was the most important reason for extraction and accounted for $54.7 \%$ of all extractions, reflecting its very high prevalence in Scotland. Only in Finland in 1984 has a
Table 5 Comparison of 1984 and 1999 data

\begin{tabular}{|c|c|c|}
\hline & 1984 & 1999 \\
\hline Mean number of extractions per patient & 2 & 1.5 \\
\hline Mean number of teeth extracted per GDP per week & 10.5 & 7.3 \\
\hline Number of dentists canvassed & 332 & 425 \\
\hline Number and proportion of dentists responding & $\begin{array}{r}208 \\
(63 \%)\end{array}$ & $\begin{array}{r}352 \\
(82.8 \%)\end{array}$ \\
\hline Number of patients & 1,082 & $\mathrm{I}, 730$ \\
\hline Number of teeth extracted & 2,190 & 2,558 \\
\hline $\begin{array}{l}\text { Number and proportion of teeth extracted } \\
\text { from regular attenders }\end{array}$ & $\begin{array}{r}891 \\
(41 \%)\end{array}$ & $\begin{array}{r}1,404 \\
(55 \%)\end{array}$ \\
\hline Proportion of males who were regular attenders & $36 \%$ & $52 \%$ \\
\hline Proportion of females who were regular attenders & $47 \%$ & $66 \%$ \\
\hline Proportion of teeth extracted for caries & $50 \%$ & $55 \%$ \\
\hline Proportion of teeth extracted for periodontal disease & $21 \%$ & $17 \%$ \\
\hline Proportion of teeth extracted for orthodontics & $7 \%$ & $10 \%$ \\
\hline $\begin{array}{l}\text { Proportion of teeth extracted for } \\
\text { pre-prosthetic reasons }\end{array}$ & $11 \%$ & $8 \%$ \\
\hline $\begin{array}{l}\text { Proportion of teeth extracted for caries from } \\
\text { irregular attenders }\end{array}$ & $61 \%$ & $70 \%$ \\
\hline $\begin{array}{l}\text { Proportion of teeth extracted for caries from } \\
\text { regular attenders }\end{array}$ & $36 \%$ & $42 \%$ \\
\hline $\begin{array}{l}\text { Proportion of teeth extracted caused by periodontal } \\
\text { disease in irregular attenders }\end{array}$ & $20 \%$ & $15 \%$ \\
\hline $\begin{array}{l}\text { Proportion of teeth extracted due to periodontal } \\
\text { disease in regular attenders }\end{array}$ & $24 \%$ & $19 \%$ \\
\hline
\end{tabular}

higher figure been recorded. With caries such a dominant risk factor for tooth loss, extractions caused by periodontal disease were much less frequent. At $16.7 \%$ of all extractions, this was the lowest rate of tooth loss for this reason reported among the featured studies. Many teeth could be lost to caries in young adults before they could 
be threatened by periodontal disease. Many of those teeth remaining would be so severely compromised by caries and restorations that they would be at great risk of extraction caused by later endodontic or other restorative problems.

There were proportionately more extractions for caries in males than in females. This could mean that males have more caries or that males are less likely to maintain restorations or that males are more likely to opt for extraction than restoration.

Caries (and its sequelae) was the major reason for extraction in all age groups over 20 years. Extractions for periodontal disease peaked in the 51-60 year age group but were still less than for caries. It may be that extractions caused by caries are happening later in the disease process, perhaps following initial attempts to treat the tooth. In other words if more teeth are restored rather than extracted then extractions will be deferred to an older age group. Thus the continuing high frequency of extractions for caries may reflect an increase in restoration prior to extraction rather than a high incidence of caries in older people.

Extractions for caries and its sequelae occurred much more often in irregular attenders; presumably a reflection of the role of extraction as the simplest solution to acute symptoms for patients without a positive attitude to dental health.

The sampling procedure and protocols for recording extractions were identical in the 1984 and 1999 studies but the methods for recruiting the sampled dentists were different. In 1984 the dentists were first invited to participate and all those who accepted were issued with survey forms to be completed during the same week. In 1999 the sampled dentists were recruited over a 3-month period and asked to complete the survey form during the next working week. This resulted in a better response rate than the first study and is a possible source of bias when comparing the two studies. The exclusion and non-response of dentists and changes in treatment philosophy over time may also have introduced bias. Comparisons with 1984 will, therefore, be restricted to obvious time trends and marked differences. Compared with 1984, orthodontics has replaced caries as the commonest reason for extraction in young people. In adults, caries has become the dominant reason for tooth loss at every age with proportionately fewer teeth extracted because of periodontal disease. It is only possible to speculate on the reasons for this shift. A simplistic, but unlikely explanation would encompass a change in disease occurrence. However, patient expectations, economic factors and treatment philosophy will change over time and may have a major influence on the decision to extract a tooth. A qualitative analysis of the decision making process is given by Kay and Blinkhorn. ${ }^{16}$ Studies on decision making with respect to extractions have been carried out by Klock. ${ }^{17,18}$ These examined the effects of the patients' perceptions and the dentist associated factors on the decision making process and found that the primary reasons for extraction were based on the disease related diagnoses. Thus the trends which have been described could reflect the effort being made to restore carious teeth and to treat periodontal disease resulting in extractions being deferred to later in life. They could also reflect more accurate periodontal diagnosis and the changing dentist and patient attitudes to the extraction of relatively symptomless, periodontally involved teeth.

In summary, although the number of teeth extracted has fallen by about $25 \%$ during the last 15 years, caries and its sequelae remain the most important cause of tooth loss throughout adult life and therefore caries prevention and maintenance of restorations are of great importance at all ages.

The authors wish to thank all the general dental practitioners who took part, Dr R Strang and his staff for data handling, and Stafford Miller Ltd for financial support.

1 Kay E J, Blinkhorn A S. The reasons underlying the extraction of teeth in Scotland. Br Dent J 1986; 60: 289-290.

2 Adult Dental Health Survey. Oral Health in the United Kingdom 1998. London: Office for National Statistics 2000, The Stationery Office.

3 Rugg Gunn A. Leader: Scientific validity? Br Dent J 1997; 182: 41.

4 Tan R T, Burke F J T. Response rates to questionnaires mailed to dentists. A review of 77 publications. Int Dent J 1997; 47: 349-354.

5 Morita M, Kimura T, Kanegae M, Ishikawa A, Watanabe T. Reasons for extraction of permanent teeth in Japan. Community Dent Oral Epidemiol 1994; 22: 303-306.

6 Hull P S, Worthington H V, Clerehugh V, Tsirba R, Davies R M, Clarkson J E. The reasons for tooth extractions in adults and their validation. J Dent 1997; 25: 233-237.

7 Ainamo J, Sarkki L, Kuhalampi M L, Palolampi L, Pirito O. The frequency of periodontal extractions in Finland. Community Dent Health 1984; 1: 165-172.

8 Cahen P M, Frank R M, Turlot J C. A survey of the reasons for dental extractions in France. J Dent Res 1985; 64: 1087-1093.

9 Agerholm D M, Sidi A D. Reasons given for extraction of permanent teeth by general dental practitioners in England and Wales. Br Dent J 1988; 164: 345-348.

10 Klock K S, Haugejorden O. Primary reasons for extraction of permanent teeth in Norway: changes from 1968 to 1988. Community Dent Oral Epidemiol 1991; 19: 336-341.

11 Murray H, Clark M, Locker D, Kay E J. Reasons for tooth extractions in dental practices in Ontario, Canada according to tooth type. Int Dent J 1997; 47: 3-8.

12 Angelillo I F, Nobile C G, Pavia M. Survey of reasons for extraction of permanent teeth in Italy. Community Dent Oral Epidemiol 1996; 24: 336-340.

13 Ong G, Yeo J F, Bhole S. A survey of reasons for extraction of permanent teeth in Singapore. Community Dent Oral Epidemiol 1996; 24: 124-127.

14 Reich E, Hiller K A. Reasons for tooth extraction in the Western States of Germany. Community Dent Oral Epidemiol 1993; 21: 379-383.

15 Stephens R G, Kogon S L, Jarvis A M. A study of the reasons for tooth extraction in a Canadian population sample. J Can Dent Assoc 1991; 57: 501-504.

16 Kay E J, Blinkhorn A S. A qualitative investigation of factors governing dentists' treatment philosophies. Br Dent J 1996; 180: 171-176.

17 Klock K S. Patients' perceptions of the decision-making process leading to extraction of permanent teeth in Norway. Community Dent Oral Epidemiol 1995; 23: 165-169.

18 Klock K S, Haugejorden O. An analysis of primary and contributing reasons for extraction of permanent teeth given by the dentist. Acta Odontol Scand 1993; 51: 371-378. 